\title{
Critical review on pharmacological properties of Brahmi
}

\author{
Review article
}

\begin{tabular}{c}
\hline Yadav Kapil Deo ${ }^{\mathbf{1}^{*}}$, Reddy KRC \\
1. Service Senior Resident, 2. Associate Professor, \\
Department of Rasa Shastra, Faculty of Ayurveda IMS, BHU, Varanasi. \\
\hline
\end{tabular}

\begin{abstract}
Water hyssop and "Brahmi" are two words used for Bacopa monneri in the traditional system of medicine. Traditionally, it was used as a brain tonic to enhance learning \& memory, and to provide relief in anxiety or epileptic disorders. The plant has also been used as a cardiac tonic, digestive aid and to improve respiratory function in cases of bronchoconstriction. Brahmi contains bacoside A \& B, Brahmin as main alkaloid and others are nicotine, herpestine. Bacoside A, B are the major constituents present in Brahmi plant in the form of saponins other than this D- mannitol, hersaponin and potassium salts are also present. In this review we discuss primarily on pharmacological properties, chemical constituents and scientific researches supporting the not only traditional use of Ayurvedic claims regarding Brahmi plant but also other physiological conditions such as antiinflammatory, cardio tonic and other pharmacological effects of BM preparations/extracts.
\end{abstract}

Key Words: Brahmi, Pharmacological properties, Chemical constituents

\section{Introduction}

Brahmi is derived from word "Brahma" the mythical creator of Hindu pantheon and brain is the centre of creative activity in human body, those compounds that improve brain health is called Brahmi. The first clear reference of Brahmi regarding augmentation of memory is found in Charak Samhita (1), where Brahmi is prescribed as a cure for mental disorder (retardation) leading to insanity. The aetiology of the mental disorder according to Charak is a combination of anxiety, weak intellect and lack of concentration. Another authentic Ayurveda treatise i.e. Susruta Samhita has described

\footnotetext{
*Corresponding Author:

Yadav Kapil Deo

Service Senior Resident,

Department of Rasa Shastra,

Faculty of Ayurveda IMS,

BHU, Varanasi.

Email: k.d.yadav1983@gmail.com
}

Brahmi as efficacious in loss of intellect and memory. It is classified as a "Medhya Rasayan" drugs used to improve memory and intellect (Medhya), has been used by Ayurvedic medical practitioners in India for almost 3000 years. Plants have been used in different formulations which are used in various disorders in traditional system of medicine and researchers supports that some natural compound present in it act as Nootropic activity (2). Active ingredients of Brahmi known as bacosides, which are responsible for improving memory, related disorders, and enhance efficiency of transmission of nerve impulse there by strengthening memory and cognition (3).The increasing demand of herbal medicine in recent years is observed which may be due to lesser side effect in comparison to recent synthetics drugs. To overcome this solution pharmaceutical industry develops in vitro system for production of medicinal plants and their extracts (4). 


\section{Description of Plants}

Bacopa monneri, a member of the Scrophulariaceae family, is a small, creeping herb with numerous branches, small oblong leaves, and light purple flowers. In India and the tropics, it grows naturally in wet soil, shallow water, and marshes. It is also found in Nepal, Srilanka, China, Taiwan, Vietnam, Florida and Southern states of USA. It is widely distributed in warmer parts of Asia, Australia, America and India commonly known as Brahmi or Indian water hyssop has been investigated (5) The herb can be found at elevations from sea level to altitudes of 4,400 feet, and is easily cultivated if adequate water is available. Flowers and fruit appear in summer and the entire plant is used for medicinal purpose (6).

\section{Ethnopharmacology:}

It is astringent, bitter, having cooling properties and is reported to improve the intellect. It is widely used for the treatment of asthma, hoarseness, dermatitis, anaemia, diabetes, cardiac disorders, insanity, and epilepsy. It is also used in boils as blood purifier, used in cataract complaints. Whole plant is used for medicinal purpose like juice of the leaves for relief in bronchitis and diarrhoea given to children, paste of the leaves is used as a remedy for rheumatism, leaves and tender stalks are reported to be eaten in the west Bengal and decoction of leaves is used in cough disorders. It is also observed that it is safe cardiac tonic, gives relief to patients from anxiety neurosis if given with ginger juice, sugar and bark extracts of Moringa oleifera. It was reported as a potent antioxidant and bronco-vasodilator.

\section{Phytochemistry:}

In view of the importance of this plant in the indigenous system of medicine, systematic chemical examinations of the plant have been carried out by several groups of researchers. Detailed investigations were first documented in 1931, when Bose and Bose reported the isolation of the alkaloid "Brahmin" from Bacopa monneri (BM) and other alkaloids like nicotine and herpestine have also been reported later (7). It was found highly toxic, when administered at a dose of $0.5 \mathrm{mg} / \mathrm{kg}$ body weight of cat, it produces a fall in the blood pressure. In therapeutic doses it action resembles with action of strychnine chemical. The isolation of D-mannitol, saponins, hersaponin and potassium salts by Sastri provided further details of the chemical components of BM (8). The major chemical entity shown to be responsible for the memory-facilitating action of BM, Bacoside A, was assigned as 3-((alpha)-L-arabinopyranosyl)-O-(beta)D-glucopyranoside-10, 20-dihydroxy-16keto-dammar-24-ene (9). It usually cooccurs with Bacoside $\mathrm{B}$, the latter differ to each other only in optical (10). Bacosides $\mathrm{A}$ and $\mathrm{B}$ possess haemolytic activity. On acid hydrolysis, Bacosides yield a mixture of aglycones, bacogenin (11), and two genuine sapogenins, jujubogenin and pseudojujubogenin (12). In addition, same authors isolated three new saponins from $\mathrm{BM}$, designated as bacopasides III, IV and $\mathrm{V}$ (13). Moreover, three new phenylethnoid glycosides, viz. monnerisides I-III along with the known analogue plantainoside $B$ have been isolated from the glycoside fraction of BM (14). Analysis of the leaves and stalks exposed, moisture 88.4; protein 2.1: fat 0.6 ; carbohydrates 5.9 ; crude fibre 1.05 ; ash $1.9 \mathrm{~g} \mathrm{/} \mathrm{100gm,} \mathrm{calcium} \mathrm{202.0;}$ phosphorus 16.0; iron 7.8 ; ascorbic acid 63.0; nicotinic acid $0.3 \mathrm{mg} / 100 \mathrm{~g}$; and energy $38 \mathrm{cal} / 100 \mathrm{~g}$. The leaves contain a sterol $\mathrm{C}_{26} \mathrm{H}_{46} \mathrm{O} . \mathrm{H}_{2} \mathrm{O}$, m p $76^{0)}$ (15).

\section{Pharmacological Properties: Anti Asthmatic Activity:}

BM extract possessed relaxant properties in tracheal muscle of rabbit and guinea-pigs with a partial contribution by (beta)-adrenoreceptor and 
prostaglandins (16). It also produced bronco dilation in anaesthetized rats (17) supported the traditional use of this plant in for various respiratory ailments (18). Bronchodilator property of extract may be reflected by antagonism of carbachol-induced effects on inspiratory and expiratory pressures. Extract exhibited a dual action on bronchoconstriction induced by carbachol. At low doses (25 and $37 \mathrm{mg} / \mathrm{kg})$, predominantly inhibited inspiratory pressure, but at a high dose $(50 \mathrm{mg} / \mathrm{kg})$ inhibited only expiratory pressure. This property of the plant extract implies that more than one mechanism of action may be responsible for bronco-dilation. Some of the possible mechanisms include (beta)adrenoreceptor activation, muscarinic receptor antagonism, prostaglandin release or interference with calcium mobilization. A more recent study by the same authors demonstrates the calcium antagonistic activity is present in ethanol extract of BM (19). In addition, it has been reported that BM methanolic extract exhibited a potent mast cell stabilizer, indicating the potential usefulness of BM leaves in allergic conditions (20).

\section{Anti cancer activity:}

Pre treatment with BM significantly reduced the acute stress (AS)induced increase in the ulcer index, adrenal gland weight, plasma glucose, aspartate aminotransferase (AST), and creatine kinase (CK) (21) in cancerous patients. This was due to presence of Bacosides present in BM, which have anticancer activity. Methanolic extract exhibited potent mast cell stabilizer (22) activity. Bacopa monneri is a known hyper accumulator of cadmium, chromium, lead $\&$ mercury and used for phytoremedy (23).

\section{Anticonvulsive}

Bacopa has been indicated as a remedy for epilepsy in Ayurvedic medicine and animal research showed anticonvulsant activity present in it, only at high doses over extended periods of time. It have been also reported that crude water extract of BM controls epilepsy in experimental animals (24). The naturally it exhibited sedative effect and significantly prolonged hypnotic action of phenobarbitone. Those substances which stimulate GABA are known to possess anticonvulsant, pain relieving and sedative effects (26). It suggests the involvement of GABA-ergic system in mediation of central nervous system (25). BM was evaluated alone and in combination with phenytoin (PHT) for its effect on PA task, maximal electroshock seizures and locomotors activity in mice (27). Both acquisition and retention of memory showed improvement without affecting PHT anti convulsive activity. Further investigations using $\mathrm{BM}$ alone or in combination with other antiepileptic drugs are warranted to explore the full potential of BM in epilepsy.

\section{Antidepressant:}

Methanolic extract of BM possess potential antidepressant activity in rodent. When given in the dose of 20 and 40 $\mathrm{mg} / \mathrm{kg}$, orally for 5 days, the extract was found to have significant antidepressant activity in forced swim and learned helplessness models of depression and was comparable to that of imipramine (28).

\section{Anti inflammatory:}

Bacopa monneri has the ability to inhibit inflammation through modulation of pro-inflammatory mediator release (29) i.e. it possesses significant antiinflammatory activity that may well be relevant to its effectiveness in the healing of various inflammatory conditions in traditional medicine (30). It also significantly inhibited 5-lipoxygenase (5LOX), 15-LOX and cyclooxygenase-2 (COX-2) activities (31). This activity may be due to presence of the triterpenoids and bacosides in it. 
Anti nociceptive activity:

Aqueous extract of Bacopa monneri (AEBM) exhibits analgesic activity through multiple pain pathways (32) i.e. involvement of $\beta_{1}$-adrenergic, $\alpha 2$ adrenergic receptors and 5-HT receptors in analgesic activity. It was also observe that when AEBM was given in combination with naloxone did not increase the latency for analgesic effect, which indicates involvement of opioid receptors in analgesic activity.

\section{Antioxidant activity:}

Alcoholic and hexane extract of BM have antioxidant properties (33) by inhibiting lipid peroxidation. A more recent study explored antioxidant effect of BM by other mechanism like inhibition of superoxide dismutase (SOD), catalase (CAT) and glutathione peroxidise (GPX) activities (34). It was also observed that the hydro alcoholic extract of the whole BM plant exhibited an inhibitory effect on superoxide released from polymorphonuclear cells in nitro blue assay (35). Sumathy et al. (2001) investigated hepato protective activity of alcoholic extract BM on morphine-treated rats (36). It may be due to decreased brain mitochondrial enzyme activity in rats (37). Methanolic extract BM is able to directly inhibit the superoxide anion formation in a dose-dependent manner due to this it reduces concentrations of nitric oxide (NO), generated (enzymatic and nonenzymatic) by activated astrocytes, might be involved in a variety of neurodegenerative diseases, such as AD, ischemia and epilepsy( 38,39$)$.

\section{Anti stress Activity:}

Standardized extract of BM possesses an adaptogenic activity. Pre treatment with low dose of BM extract significantly reversed changes in ulcer index and plasma AST only, whereas the pre treatment with higher dose significantly reversed changes in ulcer index, adrenal gland weight, $\mathrm{CK}$, and AST (40).

Anti Spasmodic Activity:

BM extract have spasmolytic activity in smooth muscles due to inhibition of calcium influx via both voltage and receptor-operated calcium channels of the cell membrane. (41) However, the absence of any modification of either nor-adrenaline or caffeineinduced contractions in the presence of BM extract suggests that this natural compound has no detectable effect on mobilization of intracellular calcium.

\section{Anxiolytic effect:}

The higher doses of BM extract produced significantly greater anxiolytic effects compared to LZP (42). However, $\mathrm{BM}$ has a distinct advantage over lorazepam (LZP) since it does not induce amnesia and has a memory-promoting action in animals and man $(43,44)$. These results was also observed by Shanker and Singh and reported that BM extract possessed an anxiolytic effect (45).

\section{Cardiovascular activity:}

Ethanolic extract of BM, shown cardiac depressive activity on left ventricular contractility, heart rate and coronary flow in isolated rabbit heart (46). It also demonstrated that protective effect of BM on pulmonary artery and aorta (47).

\section{Gastroprotective activity:}

The anti-ulcer and ulcer-healing activities of the Bacopa monneri extract may be due to its effects on various mucosal offensive and defensive factors (48). It also have beneficial role in intestinal spasm such as irritable bowel syndrome (49). It may be due to spasmolytic activity on intestinal smooth muscle, via inhibition of calcium influx across cell membrane channels. Fresh BM juice (BMJ) and BM extract has been reported to have significant anti ulcerogenic activity $(50,51,52)$. Ulcer 
protective effect of BMJ may be due to its effect on mucosal defensive factors such as enhanced mucin secretion, mucosal glycoprotein and decreased cell shedding, rather than on offensive factors such as acid and pepsin.

\section{Hepatoprotective activity:}

It was found that pre treatment with BM extract has shown to possess a significant protective effect against morphine-induced liver and kidney functions in terms of serum glutamate oxaloacetate transaminase, serum glutamate pyruvate transaminase, alkaline phosphatase, lactate dehydrogenases and gamma-glutamyl transferase activities and urea, creatinine and uric acid level respectively (53). Pre treatment of Bacoside A also prevents the elevation of LPO (Lipid Peroxidise) and activity of serum marker enzymes and maintains the antioxidant system and thus protects the rats from Diethyl nitrosamine-induced hepatic toxicity (54).

\section{Learning and memory:}

Plant extracts and isolated Bacosides have been extensively investigated in several laboratories for their neuro pharmacological effects and number of reports are available confirming their Nootropic action. Preliminary studies established that treatment with plant (55) or alcoholic extract of BM plant (56) enhanced learning ability in rats. Subsequent studies indicated that the cognition-facilitating effect was due to presence of Bacosides $\mathrm{A}$ and $\mathrm{B}$, in ethanol extract (43). These active principles, apart from facilitating learning and memory in normal rats, inhibited the amnesic effects of scopolamine, electroshock and immobili zation stress (44). The mechanism of these pharmacological actions remains conjectural. It has been suggested that bacosides induce membrane dephosphorylation, with concomitant increase in protein and RNA turnover in specific brain areas (57). BM has been shown to enhance protein kinase activity in hippocampus which could also contribute to its nootropic action (58). Administration of BM for two weeks, also reversed the depletion of acetylcholine, the reduction in acetyl cholinesterase activity and the decrease in muscarinic cholinergic receptor binding in the frontal cortex and hippocampus, induced by neurotoxin, colchicines (59). It has been suggested that the behavioural effects of cholinergic degeneration can be alleviated by a reduction in noradrenergic function (60). $\mathrm{BM}$ is known to lower nor epinephrine and increase 5-hydroxytryptamine levels in the hippocampus, hypothalamus and cerebral cortex (58), thus BM indirectly, modify Ach concentrations.

\section{Dosage:}

Traditional daily doses of Bacopa was 5- $10 \mathrm{gm}$ of non-standardized powder, $8-16 \mathrm{ml}$ of infusion, and $30 \mathrm{ml}$ daily of syrup (Brahmi). Dosages of 1:2 fluid extract are 5-12 $\mathrm{ml}$ per day for adults and 2.5-6 ml per day for children ages 6-12 years. For Bacopa extracts standardized to 20-percent Bacosides A and B, dosage is 200-400 mg daily in divided doses for adults, and for children, 100-200 mg daily in divided doses.

\section{Conclusion:}

Bacopa monneri, traditional Ayurvedic medicinal plant has been used for centuries as a memory-enhancing, antiinflammatory, analgesic, antipyretic, sedative, and antiepileptic agent. More recently, preclinical studies and clinical studies supported the cognitive enhancing effects with various extracts of BM, but the exact mechanism of its actions is still uncertain, as its multiple active constituents make its pharmacology complex. It has been suggested that BM, like Ginkgo biloba, exhibits protective and cognitive enhancing effects, to modulate the cholinergic system and to contrast oxidative stress. . 


\section{References:}

1. T Brahmanand. Charaka Chandrika Chikitsa Sthana: Varanasi, Chaukhambha Surbharti Publishers 2004.

2. Russo A, Borrelli F. Bacopa monneri, a reputed Nootropic plant: an overview. Phytomedicine 2005; 12:305-317.

3. Anon, Bacopa monneri; Monograph Altern Med. Rev. 2004 9:79-85.

4. Banerjee M, Shrivastava S. An improved protocol for in vitro multiplication of Bacopa monneri (L): J. Microbio. Biotechnol, Springer Netherlands, 2008; 24: 1355-1359.

5. Kapoor LD. CRC Handbook of Ayurvedic medicinal Plants: Florida CRC Press, Boca Raton. 1990.

6. Bone K. Clinical Applications of Ayurvedic and Chinese Herbs: Monographs for the Western Herbal Practitioner. Warwick, Queensland: Phytotherapy Press; 1996.

7. Chopra RN, Nayar L, Chopra IC. Glossary of Indian Medicinal Plants. vol. 32. Council of Scientific and Industrial Research, New Delhi. 1956.

8. Shastri MS, Dhalla NS, Malhotra CL. Chemical investigation of Herpestis monneri Linn (Brahmi). Indian J. Pharmacol. 1959; 21:303-304.

9. Chatterji N, Rastogi RP, Dhar ML. Chemical examination of Bacopa monneri Wettst: parti-isolation of chemical constituents. Indian J. Chem. 1959; 3:24-29.

10. Rastogi RP. Compendium of Indian Medicinal Plants. CSIR, New Delhi, 1990:1: pp. 118-122.

11. Chandel RS, Kulshreshtha DK, Rastogi RP. Bacogenin (A.sub.3): a new sapogenin from Bacopa monneri. Phytochemistry 1977;16:141-143.

12. Rastogi S, Pal R, Kulshreshtha DK. Bacoside A3-a triterpenoid saponin from Bacopa monneri. Phytochemistry 1994; 36:133-137.
13. Chakravarty AK, Garai S, Masuda K, Nakane T, Kawahara N. Bacopasides III-V: three new triterpenoid glycosides from Bacopa monneri. Chem. Pharm. Bull. 2003; 51: 215217.

14. Chakravarty AK, Sarkar T, Nakane T, Kawahara N, Masuda K. New phenylethanoid glycosides from Bacopa monneri. Chem. Pharm. Bull. 2002; 50, 1616-1618.

15. htpp// herbalnet.org/wholherb/bacopa_mon.as ps

16. Dar A, Channa S. Bronchodilatatory and cardiovascular effects of an ethanol extract of Bacopa monniera in anaesthetized rats. Phytomedicine 1997b; 4:319-323.

17. Nadkarni KM. The Indian Materia Medica. Columbia, MO: South Asia Books; 1988:624-625.

18. Dar A, Channa S. Calcium antagonistic activity of Bacopa monniera on vascular and intestinal smooth muscles of rabbit and guinea-pig. J. Ethnopharmacol. 1999;66:167-174.

19. Sharma R, Chaturvedi C, Tewari PV. Efficacy of Bacopa monnieri in revitalizing intellectual functions in children. J Res Edu Indian Med 1987; Jan-June: 1-12.

20. Negi KS, et al. Clinical evaluation of memory enhancing properties of Memory Plus in children with attention deficit hyperactivity disorder. Ind. $J$ Psychiatry 2000; 42: Supplement. (Abstract)

21. Rai D, Bhatia G, Palit G and Pal R. Adaptogenic effect of Bacopa monneri (Brahmi), Pharmacol. Biochem. Behav, 2003;75: 823-830.

22. Samiulla DS. Prashanth D, Amit A. Mast cell stabilising activity of Bacopa monnieri, Fitoterapia, 2001; 72:284285.

23. Tripathi YB, Chaurasia S, Tripathi E and Upadhyay A. Bacopa monniera Linn. as an antioxidant: mechanism of 
action, Indian J. Exp. Biol, 1996; 34: 523-526.

24. Shanmugasundaram ER, Akbar GK, Shanmugasundaram KR. Brahmighritham, an Ayurvedic herbal formula for the control of epilepsy. J. Ethnopharmacol. 1991; 33: 269-276.

25. Singh HK, Shanker G, Patnaik GK. Neuropharmacological and anti-stress effects of bacosides: a memory enhancer: Indian J. Pharmacol. 1996; 28: 47.

26. Shanker G, Singh HK. Anxiolytic profile of standardized Brahmi extract: Indian J. Pharmacol. 2000; 32:152.

27. Vohora D, Pal SN, Pillai KK. Protection from phenytoin-induced cognitive deficit by Bacopa monneri, a reputed nootropic plant: J. Ethnopharmacol. 2000; 71: 383-390.

28. Sairam K, Dorababu M, Goel RK, Bhattacharya SK. Antidepressant activity of standardized extract of Bacopa monniera in experimental models of depression in rats: Phytomedicine 2002; 9:207-211

29. Viji V, Helen A. Inhibition of proinflammatory mediators: role of Bacopa monniera (L.) Wettst, Inflammo J. Ethnopharmacol. 2010.

30. Channa S, Dar A, Anjum S and Yaqoob M. Anti-inflammatory activity of Bacopa monniera in rodents: J. Ethnopharmacol., 2006; 104(1-2): 286289.

31. Viji V and Helen A. Inhibition of lipoxygenases and cyclooxygenase-2 enzymes by extracts isolated from Bacopa monniera (L.) Wettst, J. Ethnopharmacol., 2008; 23, 118(2): 305-311.

32. Manju B, Jagtap AG. Exploring the possible mechanisms of action behind the antinociceptive activity of Bacopa monniera Int J Ayurveda Res. 2011; 2: 2-7

33. Tripathi YB, Chaurasia S, Tripathi E, Upadhyay A, Dubey GP. Bacopa monniera Linn. as an antioxidant: mechanism of action: Indian J. Exp. Biol. 1996; 34:523-526.

34. Bhattacharya SK, Bhattacharya A, Kumar A, Ghosal S. Antioxidant activity of Bacopa monniera in rat frontal cortex, striatum and hippocampus: Phytother. Res. 2000;14:174-179.

35. Pawar R, Gopalakrishnan C, Bhutani KK. Dammarane triterpene saponin from Bacopa monniera as the superoxide inhibitor in polymorphonuclear cells: Planta Med. 2001; 67:752-754.

36. Sumathi T, Nayeem M, Balakrishna K. Alcoholic extract of Bacopa monneri reduces the in vitro effects of morphine withdrawal in guineapig $J$ Ethnopharmacol 2002; 82:75-81

37. Sumathy T, Govindasamy S, Balakrishna K, Veluchamy G. Protective role of Bacopa monniera on morphine-induced brain mitochondrial enzyme activity in rats: Fitoterapia 2002; 73:381-385.

38. Colasanti M, Suzuki H. The dual personality of NO. TPS $2000 ; 21: 249$ 252.

39. Russo A et al.. Nitric oxide-related toxicity in cultured astrocytes: effect of Bacopa monniera: 2003b; Life Sci. 73:1517-1526.

40. D, Bhatia G, Palit G, Pal R. Adaptogenic effect of Bacopa monniera (Brahmi): Pharmacol Biochem. Behav. 2003;75: 823-830.

41. Ganguly D K, Malhotra CL, Indian J. Med. Res., 1967, 55:473

42. Bhattacharya SK, Ghosal S. Anxiolytic activity of a standardized extract of Bacopa monneri; an experimental study. Phytomedicine 1998; 5:77-82.

43. Singh HK, et al. Drugs affecting learning and memory. In:. (Eds.), Lectures in Neurobiology Wiley Eastern, 1992; 1: pp. 189-207.

44. Dhawan BN, Singh HK. Pharmacology of ayurvedic nootropic Bacopa 
monneri, Abstr. No. NR 59. Int. Conv. Biol. Psychiat1996

45. Shanker G, Singh HK. Anxiolytic profile of standardized Brahmi extract: Indian J. Pharmacol. 2000; 32:152.

46. Rashid S, Lodhi F, Ahmad M and Usmanghani K. Cardiovascular effects of Bacopa monnieri (L.) pennel extract in rabbits: Pak. J. Pharm. Sci., 1990; 3(2): 57-62.

47. Dar A, Channa S. Relaxant effect of ethanol extract of Bacopa monneri on trachea, pulmonary artery and aorta from rabbit and guinea-pig: Phytother. Res., 1999; 11: 323-325.

48. Dorababu M, Prabha T, Priyambada S, Agrawal VK. Effect of Bacopa monneri and Azadirachta indica on gastric ulceration and healing in experimental NIDDM rats: Indian J. Exp. Biol., 2004; 42:389.

49. Dar A, Channa S. Calcium antagonistic activity of Bacopa monneri on vascular and intestinal smooth muscles of rabbit and guinea-pig: J. Ethnopharmacol, 1999; 66: 167- 174.

50. Goel RK, Sairam K, Babu MD and Tavares IA. In vitro evaluation of Bacopa monneri on anti-Helicobacter pylori activity and accumulation of prostaglandins: Phytomed., 2003; 10: 523-527.

51. Rao CHV, Sairam K, Goel RK. Experimental evaluation of Bacopa monniera on rat gastric ulceration and secretion: Indian J. Physiol. Pharmacol. 2000; 44:435-441.

52. Sairam K, Rao CV, Babu MD, Goel RK. Prophylactic an curative effects of Bacopa monniera in gastric ulcer models. Phytomedicine 2001; 8:423430.

53. Sumathi T, Niranjali, Devaraj S. Effect of Bacopa monniera on liver and kidney toxicity in chronic use of opioids, Phytomed. 2009; 16(10): 897903.
54. Janani P, Sivakumari K, Parthasarathy C. Hepatoprotective activity of bacoside A against Nnitrosodiethylamine-induced liver toxicity in adult rats: Cell Biol. Toxicol., 2008; 25(5): 425-434

55. Malhotra CL, Das PK. Pharmacological studies of Herpestis monneri Linn. (Brahmi): Indian J. Med. Res. 1959; 47:294-305

56. Singh HK, Dhawan BN. Effect of Bacopa monniera extract on avoidance responses in rat. J. Ethnopharmacol. 1982;5:205-214.

57. Singh HK, Srimal RC, Srivastava AK, Garg NK, Dhanwan BN. Neuropsychopharmacological effects of Bacosides A and B. Proceedings of the Fourth Conference on Neurobiology Learning Memory, Abstract No. 79. Irvine California. 1990.

58. Singh HK, Dhawan BN. Neuropsychopharmacological effects of the Ayurvedic nootropic Bacopa monniera Linn (Brahmi): Indian J. Pharmachol. 1997; 29:359-365.

59. Bhattacharya SK, Kumar A, Ghosal S. Effect of Bacopa monneri on animal models of Alzheimer's disease and perturbed central cholinergic markers of cognition in rats. In: Siva Sankar, D.V. (Ed.), Molecular Aspects of Asian Medicines. PJD Publications. 1999.

60. Sara SJ. Noradrenergic-cholinergic interaction: its possible role in memory dysfunction associated with senile dementia: Arch. Gerontol. Geriatr. 1989; 1:99-108.

61. Das A, Shanker G, Nath C, Pal R, Singh S, Singh, H. A comparative study in rodents of standardized extracts of Bacopa monneri and Ginkgo biloba. Pharmacol. Biochem. Behav. 2002; 73:893-900. 